\title{
PERCEPÇÕES DE PUÉRPERAS SOBRE OS BENEFÍCIOS DA AMAMENTAÇÃO NA PRIMEIRA HORA PÓS-PARTO
}

Karla Cecília Celestino Moura ${ }^{1}$, Priscilla Ferreira Gonçalves ${ }^{1}$, Joanilva Ribeiro Lopes ${ }^{2}$, Paulo Henrique Tolentino Moura ${ }^{3}$, Antônio Prates Caldeira ${ }^{4}$, Lucinéia de Pinho ${ }^{5}$

RESUMO: A amamentação precoce é uma estratégia para a promoção ao aleitamento materno no Brasil, mas poucos estudos avaliam a aplicação dessa prática do ponto de vista das mães. Em uma abordagem qualitativa, investigaram-se as percepções de puérperas sobre a amamentação na primeira hora pós-parto. Os dados foram coletados pela observação dos princípios éticos e os relatos foram classificados nas categorias: Oque éo leite materno; Beneficios da amamentação precoce para mãe e filho; e Orientações e prática da amamentação precoce. Embora reconhecessem o leite materno como alimento adequado para o desenvolvimento do bebê, as puérperas possuíam apenas informações gerais sobre aleitamento materno e a maioria desconhecia a teoria e a prática da amamentação precoce. Os achados apontam a necessidade de se conscientizar as gestantes sobre a importância da amamentação precoce durante o acompanhamento pré-natal. DESCRITORES: Aleitamento materno; Mães; Saúde da criança.

\section{PERCEPCIONES DE PUÉRPERAS SOBRE LOS BENEFICIOS DEL AMAMANTAMIENTO EN LA PRIMERA HORA DESPUÉS DEL PARTO}

RESUMEN: El amamantamiento precoz es una estrategia para la promoción al amamantamiento materno en Brasil, pero pocos estudios evalúan la aplicación de esa práctica del punto de vista de las madres. Con un abordaje cualitativo, fueron investigadas las percepciones de puérperas sobre el amamantamiento en la primera hora posparto. Los datos fueron recogidos por la observación de los principios éticos y los relatos fueron clasificados en las categorías: Lo qué es la leche materna; Beneficios del amamantamiento precoz para madre e hijo; y Orientaciones y práctica del amamantamiento precoz. A pesar de reconocerse la leche materna como alimento adecuado para el desarrollo del bebé, las puérperas tenían solamente informaciones generales acerca del amamantamiento materno y la mayoría desconocía la teoría y práctica del amamantamiento precoz. Los resultados apuntan la necesidad de concientizar a las gestantes sobre la importancia del amamantamiento precoz durante el acompañamiento prenatal. DESCRIPTORES: Amamantamiento materno; Madres; Salud del niño.

\section{PERCEPTIONS OF PUERPERAS REGARDING THE BENEFITS OF BREASTFEEDING IN THE FIRST HOUR FOLLOWING BIRTH}

\begin{abstract}
Early breastfeeding is a strategy for promoting breastfeeding in Brazil, but few studies have evaluated the application of this practice from the point of view of the mothers. The puerperas' perceptions regarding breastfeeding in the first hour following birth were investigated, using a qualitative approach. The data were collected observing ethical principles and the reports were classified in the following categories: What is breast milk?; The benefits of early breastfeeding for mother and child; and, guidance and practice of early breastfeeding. Although they recognize breast milk as an appropriate food for the baby's development, the puerperas have only general information about breastfeeding, and the majority are unaware of the theory and practice of early breastfeeding. The findings indicate the need to raise pregnant women's awareness regarding the importance of early breastfeeding during the prenatal monitoring.
\end{abstract}

DESCRIPTORS: Breastfeeding; Mothers; Child's health

${ }^{1}$ Enfermeira. Faculdade Santo Agostinho. Montes Claros-MG-Brasil

${ }^{2}$ Enfermeira. Especialista em Controle de Infecção e em Educação Profissional na Área de Saúde. Professora da Faculdade Santo Agostinho. Montes Claros-MG-Brasil

${ }^{3}$ Médico. Prefeitura Municipal de Itacarambi. Itacarambi-MG-Brasil

${ }^{4}$ Médico Pediatra. Doutor em Ciências da Saúde. Professor da Universidade Estadual de Montes Claros. Montes Claros-MG-Brasil

${ }^{5}$ Nutricionista. Doutora em Ciências da Saúde. Professora da Faculdade Santo Agostinho. Montes Claros-MG-Brasil 


\section{INTRODUÇÃO}

Rotinas de cuidados imediatos ao recém-nascido disseminadas entre as maternidades e a alta incidência de cesarianas e analgesia de parto prorrogam o início do contato entre mãe e filho ${ }^{(1)}$. A demora desse contado pode comprometer a eficiência na sucção, prevalência e duração da lactação, relação mãe/filho, expulsão da placenta e involução uterina da mãe, colonização do intestino do recém-nascido por microrganismos da microbiota cutânea materna, imunoproteção do recém-nascido com anticorpos presentes no colostro, e a prevenção de icterícia e hipoglicemia, e manutenção da temperatura corporal do bebê $\hat{e}^{(2)}$. Para evitar isso, a Iniciativa Hospital Amigo da Criança (IHAC) estabeleceu um conjunto de ações pró-amamentação que é difundido e patrocinado pela Organização Mundial da Saúde e pelo Fundo das Nações Unidas pela Infância. Nesse programa de 10 passos, o quarto passo corresponde à amamentação na primeira hora de vida, também chamada de amamentação precoce ${ }^{(3)}$.

A amamentação precoce é fundamental para estabelecimento do contato mãe-filho, especialmente porque nas primeiras horas de vida a maioria dos bebês está em estado de alerta e tem facilidade para encontrar o mamilo e iniciar a amamentação ${ }^{(4)}$. Isso acontece porque a compressão da cabeça e a hipóxia impostas ao bebê durante as contrações do parto elevam seus níveis de catecolaminas circulantes, o que aumenta sua sensibilidade olfativa e promove o início da amamentação ${ }^{(4)}$.

Os níveis de catecolaminas são mantidos por cerca de 60 minutos, e após três ou quatro horas, quando o recém-nascido entra na fase de sono, eles caem, comprometendo o encontro do mamilo, abocanhamento correto e estabelecimento do aleitamento materno ${ }^{(4)}$. Além disso, há estudos que mostram que mulheres que vivenciam o contato com o bebê prolongam o aleitamento materno como alimento exclusivo ${ }^{(2)}$. Contudo, o aleitamento na primeira hora de vida é realizado por, aproximadamente, $43 \%$ das mães brasileiras apenas ${ }^{(4)}$. Isso mostra que se deve investir na implementação do quarto passo da IHAC, seja em maternidade particular ou conveniada ao SUS, filantrópica ou militar. A amamentação precoce deveria ser incentivada desde o acompanhamento pré-nata ${ }^{(4)}$ e encorajada na sala de parto $^{(5)}$, especialmente devido o efeito protetor sobre a mortalidade neonatal ${ }^{(6)}$.

O baixo índice de amamentação precoce no Brasil reflete, em parte, a falta de preparo das equipes de saúde que conduzem o parto e promovem o afastamento entre mãe e bebê. Ainda assim, as puérperas são elemento ativo no processo de amamentação e, para subsidiar o desenvolvimento de estratégias para implementação do quarto passo IHAC, é preciso que se conheçam suas vivências e percepções do contato precoce e amamentação. Considerando a escassez de estudos com essa abordagem, o presente trabalho investiga e descreve a concepção das puérperas quanto aos benefícios da amamentação precoce.

\section{MÉTODO}

Realizou-se um estudo descritivo com abordagem qualitativa que procurou compreender o fenômeno do aleitamento materno na primeira hora pós-parto na percepção de puérperas. Adotou-se essa metodologia porque ela abarca a totalidade dos seres humanos ao concentrar-se na experiência vivida, além de permitir a apresentação de contribuições no processo de mudança, criação ou formação de opiniões de determinado grupo e, em maior grau de profundidade, interpretar particularidades dos comportamentos ou atitudes dos indivíduos ${ }^{(7)}$.

O estudo foi realizado de abril a maio de 2011 na Maternidade Maria Barbosa do Hospital Universitário Clemente de Faria em Montes Claros - Minas Gerais, Brasil. Essa maternidade, criada em 1992, atende mensalmente cerca de $185 \mathrm{mu}-$ lheres, é adepta à IHAC e serve como referência regional para as gestações de alto risco; recentemente recebeu o título de "Maternidade Segura".

Dada a natureza qualitativa da investigação, não houve cálculo do tamanho amostral, e o número de participantes foi definido pela técnica de saturação. Assim, participaram do estudo 23 mulheres em período pós-parto que estavam internadas na enfermaria do hospital. Todas eram maiores de idade e assinaram o Termo de Consentimento Livre e Esclarecido. Em concordância com as Resoluções n. 196 de 10/10/96 e n. 251 de 07/08/97 da CONEP, o estudo foi realizado mediante aprovação pelo Comitê de Ética em Pesquisa da Universidade Estadual de Montes Claros, Minas Gerais, Brasil, protocolo n. 2565.

A coleta de dados foi feita por meio de uma entrevista semiestruturada e seguindo um roteiro de pesquisa. As perguntas deram liberdade ao entrevistador para desenvolver cada situação em qualquer direção que considerou adequada, visto que sua função foi meramente de incentivo. Os dados foram coletados durante a permanência das mulheres nos quartos da 
enfermaria da Maternidade para não gerar desconforto às mesmas.

As entrevistas foram realizadas entre quatro minutos e meio a 12 minutos e 15 segundos. As perguntas norteadoras foram: o que é o leite materno; os benefícios do aleitamento materno para mãe e filho; orientações e prática do aleitamento materno na primeira hora de vida; benefícios (para mãe e filho) do aleitamento materno na primeira hora de vida. As entrevistas foram gravadas, e para as mães que não aceitaram a gravação, as falas foram anotadas. Em seguida, os dados foram transcritos na íntegra utilizando-se códigos ao invés dos nomes, a fim de manter o anonimato das participantes.

Os dados foram examinados de acordo com a análise de conteúdo, que é operacionalizada em três fases: pré-análise, exploração do material e tratamento dos resultados. Dessa forma, as falas das participantes foram analisadas, as ideias coincidentes e divergentes foram sintetizadas e as opiniões enquadradas dentro de categorias.

\section{RESULTADOS}

Os dados de caracterização das participantes (Tabela 1) mostraram que a maioria tinha entre 21 e 25 anos de idade e que mais da metade delas era casada. Quanto à escolaridade, a minoria das mães tinha ensino médio completo. A maioria das mães estava tendo o primeiro ou segundo filho.

A análise e agrupamento dos relatos, identificados de R1 a R23, permitiram construir categorias. Assim, a

Tabela 1 - Caracterização dos entrevistados. Montes ClarosMG-Brasil, 2010

\begin{tabular}{lcc}
\hline Características & $\mathbf{n}$ & $\mathbf{\%}$ \\
\hline Faixa Etária & 15 & 65,2 \\
21-30 anos & 8 & 34,8 \\
31-40 anos & & \\
Situação conjugal & 21 & 91,3 \\
Casadas/União Estável & 2 & 8,7 \\
Solteiras & & \\
Grau de Instrução & 1 & 4,3 \\
Analfabeta & 4 & 17,4 \\
$1^{\circ}$ grau completo & 8 & 34,8 \\
$2^{\circ}$ grau incompleto & 10 & 43,5 \\
$2^{\circ}$ grau completo & & \\
Paridade & 14 & 60,9 \\
1 a 2 & 9 & 39,1 \\
\hline 3 & $\mathbf{2 3}$ & $\mathbf{1 0 0}$ \\
\hline Total &
\end{tabular}

primeira categoria foi composta por impressões sobre o que é leite materno:

É o alimento do bebê [...]. Que vai fazer ele ficar forte bem desenvolvido. [...] eu acho o leite materno muito bom pras criancinha [...] é a melhor coisa da mãe [...] criação de Deus que nenhuma fábrica sabe fazer. (R1)

É o alimento do bebê [...]. Que vai fazer ele ficar forte. (R2)

Oleite materno pra mim é um meio de vida [...]. Porque através dele que meu filho vai ter assim [...] capacidade de ganhar peso, de não ficar doente. Então é o melhor pra ele [...]. Muita gente não dá o peito [...] por capricho [...]. Mas eu dou porque é com o meu leite que meu neném vai viver até os seis meses. (R3)

A segunda categoria de respostas consistiu na percepção de benefícios da amamentação precoce para mãe e filho. Essas vantagens foram principalmente descritas para o bebê (R4 a R6; R10), embora algumas mães não tenham identificado benefícios para o bebê (R7 a R9) ou para a mãe (R10):

Ela fica mais quietinha com esse primeiro contato. (R4)

Fica mais calmo na hora que tá com a mãe. (R5)

[...] o neném fica mais calmo. (R6)

Não sei te falar não. (R7-R9)

Ela fica mais quietinha com esse primeiro contato [...] pra mim eu já não sei [...]. (R10)

A terceira categoria de respostas compreendeu orientações e prática da amamentação precoce. Os relatos mostram a falta de orientação (R11 a R13) ou de assimilação (R14) das informações, além de dificuldades na prática da amamentação precoce por problemas relacionados à cesariana (R15) ou do recém-nascido (R16 e R17). Ainda assim, várias mães amamentaram dentro do período de 30 minutos pós-parto (R18 a R21):

Não recebi [...] então não sei te falar não. (R11)

Não recebi não [...]. Era pra ter recebido? (R12)

Não recebi. (R13) 
Recebi sim [...]. Espera aí, não estou lembrando não [...] quando eu entro no hospital é dificil lembrar. (R14)

Eu fiz cesariana, porque eu fiz ligação [...]. Na hora, na hora não colocou não [...] após meia hora. (R15)

Eu recebi a orientação só que não deu para por não. Ela teve que ficar na estufa tomando uns remedinhos porque nasceu muito cansada. (R16)

[...] eu não pude colocá-los para mamar porque nasceram de 3 e de 7 meses. Um nasceu morto, o mais pequenininho deles, e os outros dois, o menino e a menina, foram para estufa. (R17)

Colocaram ele pra mamar sim [...]. Uns 20 minutos depois. (R18)

Colocou ele pra mamar sim, só que meia hora depois. (R19)

Na hora, na hora não colocou não [...] meia hora depois. (R20)

Colocou ele pra mamar sim só que meia hora depois [...] meu parto foi cesária. (R21)

\section{DISCUSSÃO}

Para mãe e filho usufruírem de maiores benefícios da amamentação, essa prática deve ser iniciada ainda na primeira hora pós-parto ${ }^{(6)}$. Apesar disso, o presente estudo revela pontos falhos na adoção da prática da amamentação precoce. A detecção dessas deficiências foi possibilitada pela metodologia investigativa adotada que apresentou o problema de forma qualitativa e pelas percepções das puérperas.

A estratégia investigativa adotada no presente estudo tem uma limitação reconhecida por vários autores, que é o viés de memória das entrevistadas, causado pelo cansaço do estresse pós-parto e procedimentos invasivos $^{(8)}$. Ainda assim, as percepções pós-parto permitiram captar momentos marcantes desse período e, apesar da fragilidade das puérperas, elas retrataram, mesmo que imprecisamente, as impressões mais fortes que viveram.

A população estudada era jovem, com menos de 30 anos de idade. Pouco mais da metade das mães era casada ou possuía união estável, mas como mostrado em outro estudo, isso não tem grande impacto na prática da amamentação $^{(4)}$. Já a baixa escolaridade da população estudada pode comprometer o aleitamento ${ }^{(4-5)}$, pois a falta de conhecimentos escolares básicos dificulta $o$ entendimento sobre os benefícios da amamentação e interfere negativamente no desenvolvimento do compromisso de amamentar. Isso reforça a necessidade do acompanhamento das mães por equipes de Saúde da Família, desde o pré-natal ao puerpério imediato e pós-parto, pois além de esclarecer as mães, especialmente as de baixa escolaridade, essa ação promove a prática da amamentação ${ }^{(9)}$. A conscientização da importância da amamentação é particularmente necessária para mães que, como a maioria das entrevistadas, estão gerando o primeiro ou segundo filho, pois aquelas que não tiveram a experiência de amamentar outros filhos têm maior dificuldade em iniciar a amamentação ${ }^{(10)}$.

Nas percepções das puérperas sobre o significado do leite materno, elas citaram que o leite materno é o melhor alimento para o filho, e que vai contribuir para o crescimento e desenvolvimento da criança (R1 a R3). Em geral, as mães entendem que a amamentação proporciona boa condição de saúde e desenvolvimento para a criança ${ }^{(10)}$. O significado atribuído ao leite materno remete sempre ao melhor para o filho, e é referido como meio para sobrevivência da criança, e também irreproduzível uma vez que só pode ser oferecido pela mãe. A experiência da amamentação aliada ao reconhecimento dos valores nutritivos e afetivos faz com que a puérpera tenha facilidade na continuidade do aleitamento materno e também na valorização da experiência de amamentar logo após o nascimento ${ }^{(11)}$.

Apesar do conhecimento geral sobre a importância da amamentação, o quarto passo do programa de 10 passos para o aleitamento da IHAC, que corresponde ao aleitamento nos primeiros minutos de vida do recém-nascido, é ainda pouco difundido. Pelo relato das entrevistadas sobre as vantagens do aleitamento materno na primeira hora de vida, elas entendiam que esse procedimento é um meio de acalmar o bebê (R4 a R6), como já relatado em outros estudos ${ }^{(12)}$. Essa resposta parece ser intuitiva, e os benefícios reconhecidos relacionados essencialmente ao filho, embora algumas mães não tenham nenhuma informação concreta sobre o assunto (R7 a R9). Quando as puérperas são questionadas sobre os benefícios da amamentação precoce para a mãe, percebe-se a falta de informação (R10), que é um dos empecilhos apontados pelos profissionais dos centros obstétricos para que essas iniciem a amamentação na sala de parto ${ }^{(2)}$.

Uma boa proporção de gestantes brasileiras não 
recebe qualquer informação sobre aleitamento materno durante o pré-natal ${ }^{(13)}$. Corroborando o fato, puérperas entrevistadas relataram não ter recebido informação sobre o aleitamento materno nas orientações pré-natais, e por isso não foram capazes de relatar os benefícios da prática (R11 a R13). De acordo com os depoimentos, percebe-se que as mães que não receberam orientação anteriormente ao parto tiveram mais dificuldade de manter o aleitamento materno. Em outra situação, as puérperas até recebem a orientação quanto ao assunto, mas por algum motivo, não sabem relatar ao entrevistador.

Mães submetidas à cesariana muitas vezes não são estimuladas a amamentar logo após o parto por causa dos efeitos da anestesia e procedimento cirúrgico; dificuldades neste sentido foram relatadas (R15, R21). Além disso, o procedimento causa exaustão e ânsia à mãe, de modo a interferir negativamente na amamentação ainda na sala de parto $^{(2)}$; o parto cesariano pode reduzir pela metade a prevalência da amamentação na primeira hora pós-parto ${ }^{(4)}$.

Houve mães que, apesar de terem recebido as orientações para a prática do aleitamento na primeira hora de vida, não puderam praticar em virtude de intercorrências com o filho (R16, R17). A prevalência do aleitamento materno na primeira pós-parto pode ser reduzida à metade em recém-nascidos com intercorrências ${ }^{(4)}$.

Pelos relatos obtidos, o tempo para a primeira mamada não excedeu, em vários casos, 30 minutos (R18 a 21). Essa percepção de tempo é imprecisa visto que há uma tendência das mães arredondarem o tempo estimado para a primeira mamada ${ }^{(13)}$. Portanto, pela percepção das puérperas o aleitamento materno na Maternidade estudada foi realizado, em geral, na primeira hora pós-parto.

Com base nas percepções das puérperas, sugere-se que a maior participação da equipe de enfermagem é essencial para efetiva implantação do quarto passo da IHAC, pois são esses profissionais que orientam e auxiliam as mães dentro dos protocolos de atendimento das instituições de saúde. Mas, o incentivo a esse tipo de ação não deve ser mecanizada, isto é, a equipe de enfermagem deve conduzir a amamentação precoce com respeito e acolhimento ao binômio mãe-filho a fim de estabelecer um vínculo efetivo e duradouro entre ambos $^{(14)}$. Nesse processo, é importante haver também a participação ativa das puérperas, não apenas recebendo e aceitando a orientação, mas se conscientizando e refletindo sobre a importância dessa ação, de modo que tenham iniciativa para estabelecer o contato preco$\mathrm{ce}^{(14)}$. Esse é outro campo de intervenção da equipe de enfermagem que pode ser capacitada para, através de ações educativas, preparar as mães para o aleitamento precoce durante o pré-natal.

\section{CONSIDERAÇOES FINAIS}

Com esse estudo, concluiu-se que as puérperas possuem conhecimento sobre o aleitamento materno, mas não o relacionam à primeira hora de vida do bebê, de modo que elas não têm, por si só, o ímpeto de amamentar as crianças precocemente. Nesse sentido, o acompanhamento da mulher pelas equipes de Saúde da Família, desde o pré-natal ao puerpério imediato e pós-parto, pode contribuir para elucidar dúvidas e promover a amamentação, especialmente se for adequado para mulheres com baixa escolaridade conforme detectado na população estudada.

Contudo, não basta que a mãe esteja informada. Ela precisa estar inserida em um ambiente favorável e encontrar apoio no profissional de saúde, pois considerando que a amamentação se inicia, frequentemente, no hospital, é de responsabilidade dos profissionais de saúde, e especialmente da equipe de enfermagem, proporcionar às mães orientações e conhecimentos técnicos e demonstrar interesse à essa prática, promovendo o afeto entre mãe-filho.

\section{REFERÊNCIAS}

1. Matos TA, Souza MS, Santos EKA, Velho MB, Seibert ERC, Martins NM. Contato precoce pele a pele entre mãe e filho: significado para mães e contribuições para a enfermagem. Rev. bras. enferm. [Internet] 2010;63(6) [acesso em mai 2011]. Disponível: http:// dx.doi.org/10.1590/S0034-71672010000600020

2. Pillegi MC, Policastro A, Abramovici S, Cordioli E, Deutsch AD. A amamentação na primeira hora de vida e a tecnologia moderna: prevalência e fatores limitantes. Einstein. 2008;6(4):467-72.

3. Souza MFL, Ortiz PN, Soares PL, Vieira TO, Vieira GO, Silva LR. Avaliação da promoção do aleitamento materno em Hospitais Amigos da Criança. Rev. paul. pediatr. [Internet] 2011;29(4) [acesso em jan 2012]. Disponível: http://dx.doi.org/10.1590/S010305822011000400006

4. Boccolini CS, Carvalho ML, Oliveira MIC, Vasconcellos AGG. Fatores associados à amamentação na primeira 
hora de vida. Rev. Saúde Públ. [Internet] 2011;1(45) [acesso em abr 2012]. Disponível: http://dx.doi.org/10.1590/ S0034-89102010005000051

5. Narchi NZ, Fernandes RAQ, Dias LA, Novais DH. Variáveis que influenciam a manutenção do aleitamento materno exclusivo. Rev Esc Enferm USP. [Internet] 2009;1(43) [acesso em mai 2011]. Disponível: http:// dx.doi.org/10.1590/S0080-62342009000100011

6. Boccolini CS, Carvalho ML, Oliveira MIC, PérezEscamilla R. A amamentação na primeira hora de vida e mortalidade neonatal. J Pediatr. [Internet] 2013;89 [acesso em ago 2013]. Diponível: http://dx.doi. org/10.1016/j.jped.2013.03.005

7. Moraes VLC. Introdução às técnicas qualitativas de pesquisa aplicadas em saúde. Rev. Bras. Saude Mater. Infant. [Internet] 2010;10(2) [acesso em ago 2013] Disponível: http://dx.doi.org/10.1590/S151938292010000200014

8. Barbosa RW, Oliveira AE, Zandonade E, Santos Neto ET. Memória das mães sobre amamentação e hábitos de sucção nos primeiros meses da vida de seus filhos. Rev. paul. pediatr. [Internet] 2012;30(2) [acesso em ago 2013] Disponível: http://dx.doi.org/10.1590/S010305822012000200005

9. Souza-Filho MD, Gonçalves-Neto PNT, Martins MCC. Avaliação dos problemas relacionados ao aleitamento materno a partir do olhar da enfermagem. Cogitare enferm. [Internet] 2011;16(1) [acesso em out 2012]. Disponível: http://ojs.c3sl.ufpr.br/ojs2/index.php/ cogitare/article/download/21114/13940

10. Silva DDF, Lima DL, Rosito DB, Ribeiro SMF, Figueiredo MC. Percepções e saberes de um grupo de gestantes sobre aleitamento materno - um estudo qualitativo. RFO. [Internet] 2008;13(2) [acesso em jan 2010]. Disponível: http://www.upf.br/download/editora/ revistas/rfo/13-02/01.pdf

11. Barbosa V, Orlandi FS, Dupas G, Beretta MIR, Fabbro MRC. Aleitamento materno na sala de parto: a vivência da puérpera. Cienc cuid. saude. [Internet] 2010;9(2) [acesso em mar 2011]. Disponível: http:// eduemojs.uem.br/ojs/index.php/CiencCuidSaude/ article/viewFile/11249/6088

12. Rosa R, Gasperi BL, Monticelli M, Martins FE, Siebert ERC, Martins NM. Mãe e filho: os primeiros laços de aproximação. Esc. Anna Nery. [Internet] 2010;14(1) [acesso mai 2012]. Disponível: http://dx.doi.org/10.1590/ S1414-81452010000100016
13. Boccolini CS, Carvalho ML, Oliveira MIC, Leal MC, Carvalho MS. Fatores que interferem no tempo entre o nascimento e a primeira mamada. Cad. Saúde Pública. [Internet] 2008;24(11) [acesso fev 2012]. Disponível: http://dx.doi.org/10.1590/S0102-311X2008001100023

14. Matos TA, Souza MSS, Santos EKA, Velho MB, Seibert ELC, Martins NM. Contato precoce pele a pele entre mãe e filho: significado para mães e contribuições para a enfermagem. Rev. bras. enferm. [Internet] 2010;63(6) [acesso fev 2012]. Disponível: http://dx.doi.org/10.1590/ S0034-71672010000600020

Cogitare Enferm. 2014 Jan/Mar; 19(1):123-8 